\title{
PENGARUH TAX AMNESTY, PENGETAHUAN PERPAJAKAN, DAN KESADARAN PERPAJAKAN TERHADAP KEPATUHAN WAJIB PAJAK PADA KANTOR PELAYANAN PAJAK (KPP) PRATAMA PATI
}

\author{
Nurul Arvi Kusumaningrum ${ }^{1}$, Ida Nur Aeni ${ }^{2}$ \\ Program Studi Akuntansi, Fakultas Ekonomi dan Bisnis, Universitas Muria Kudus \\ 1․ nurularvi24@gmail.com \\ ida.nuraeni@umk.ac.id
}

\begin{abstract}
ABSTRAK
Penelitian ini bertujuan untuk menganalisis pengaruh tax amnesty, pengetahuan perpajakan, dan kesadaran perpajakan terhadap kepatuhan wajib pajak. Sampel dalam penelitian ini adalah 100 wajib pajak yang ada di Kpp Pratama pati, baik wajib pajak orang pribadi maupun wajib pajak badan. Data yang di gunakan dalam penelitian ini adalah data primer dengan cara penyebaran kuisioner kepada responden. Pemilihan sampel dalam penelitian ini dengan menggunakan accidental sampling. Metode analisis yang di gunakan adalah analisis regresi linier berganda.

Hasil penelitian ini menunjukan bahwa tax amnesty tidak berpengaruh dan tidak signifikan terhadap kepatuhan wajib pajak. Pengetahuan perpajakan tidak berpengaruh dan tidak signifikan terhadap kepatuhan wajib pajak. Kesadaran perpajakan berpengaruh positif dan signifikan terhadap kepatuhan wajib pajak.
\end{abstract}

Kata Kunci: tax amnesty, pengetahuan perpajakan, kesadaran perpajakan, kepatuhan wajib pajak.

\section{ABSTRAK}

This study aims to analyze the influence of tax amnesty, tax knowledge, and tax awareness on taxpayer compliance. The sample in this study were 100 taxpayers in Kpp Pratama pati, both individual taxpayers and corporate taxpayers. The data used in this study is primary data by distributing questionnaires to respondents. Sample selection in this study using accidental sampling. The analytical method used is multiple linear regression analysis.

The results of this study indicate that tax amnesty has no effect and is not significant on taxpayer compliance. Knowledge of taxation has no effect and is not significant on taxpayer compliance. Tax awareness has a positive and significant effect on taxpayer compliance.

Keywords: tax amnesty, taxation knowledge, tax awareness, obedience of tax payers.

\section{PENDAHULUAN}

Sumber pendapatan negara berasal dari dua faktor, yaitu faktor dari luar (Ekternal) dan faktor dari dalam negeri (Internal). Faktor ekternal salah satunya di dapat dari pinjaman dari luar negeri. Sedangkan faktor internal di dapat dari pendapatan pajak. Pemerintah selalu 
berupaya untuk meningkatkan jumlah pajak untuk memenuhi Anggaran pendapatan dan belanja daerah. Karena pada tahun-tahun sekarang, pajak menjadi pendapan internal yang paling besar dalam APBD.

Pemerintah berupaya untuk meningkatkan reformasi perpajakan dengan merubah sistem pemungutan pajak dari office assessment menjadi self assessment. Penelitian yang di lakukan oleh Sari dan Fidiana (2017) official assessment system merupakan sistem yang memberikan kepercayaan penuh kepada wajib pajak untuk mendaftar, menghitung, membayar dan melaporkan sendiri kewajiban perpajakan sesuai peraturan perundangundangan perpajakan yang berlaku. Pemerintah selalu berharap agar dapat meningkatkan jumlah penerimaan pajak dan kepatuhan wajib pajak dari waktu ke waktu.

Dalam mencapai target yang di tetapkan dalam APBN ada berbagai kendala dalam pengumpulan pajak. Salah satu kendala yang menghambat pengumpulan pajak adalah kepatuhan wajib pajak. Kepatuhan wajib pajak adalah perilaku wajib pajak dalam melakukan kewajiban membayar pajak, melakukan kewajiban perpajakan, dan mengunakan hak perpajakan dengan tetap menaati peraturan perpajakan yang berlaku. Banyak wajib pajak berangapan bila kewajiban membayar pajak merupakan suatu beban dan menjadi momok bagi mereka sehingga membayar pajak atau cenderung melakukan penghindaran pajak (Sari dan Fidiana, 2017). Apabila wajib pajak melakukan pembayaran pajak yang tepat waktu maka wajib pajak bisa di katakan wajib pajak yang patuh.

Karena masih banyaknya masyarakat yang belum patuh dalam pembayaran pajak maka pemerintah mengeluarkan kebijakan baru yang di kenal dengan nama tax amnesty (pengampunan perpajakan). Menurut Rahayu (2017) Tax amnesty adalah pengapusan pajak yang seharusnya terutang, tidak di kenai sanksi administrasi peperpajakan dan saknsi pidana di bidang perpajakan, dengan cara pengungkapan harta dan membayar hutang tebusan sebagaimana di atur dalam Undang-undang No 11 tahun 2016 tentang pengampunan perpajakan. Pemerintah indonesia perlu memberikan tax amnesty kepada wajib pajak karena tax amnesty merupakan harta milik warga negara itu sendiri, baik warga negara yang bertempat tinggal di dalam negeri maupun yang bertempat tinggal di luar negri, baik yang memiliki NPWP maupun yang tidak memiliki harta lain selain yang telah di laporkan dalam SPT tahunan pajak. 
Selain tax amnesty faktor yang mempengarui kepatuhan wajib pajak adalah pengetahuan perpajakan. Pengetahuan perpajakan adalah informasi pajak yang dapat di gunakan wajib pajak sebagai dasar untuk bertindak, mengambil keputusan, dan untuk menempuh arah atau strategi tertentu sehubungan dengan pelaksanaan hak dan kewajibanya (Sari dan Fidiana, 2017). Dengan pengetahuan dan wawasan tentang perpajakan maka wajib pajak akan memiliki kemauan untuk membayar pajak.

Kesadaran dari wajib pajak juga sangat perpengaruh pada tingkat kepatuhan membayar pajak. Kesadaran wajib pajak adalah pemahaman yang mendalam pada seseorang atau badan yang terwujud dalam pemikiran, sikap, dan tingkah laku untuk melaksanakan hak dan kewajiban perpajakan sesuai dengan ketentuan peraturan perundang-undangan karena memahami bahwa pajak sangat penting untuk pembiayaan nasional (Agustinigsih, 2016). Menurut penelitian yang di lakukan Tiraada (2013) kesadaran perpajakan memberikan pengaruh yang besar terhadap kepatuhan wajib pajak.

Menurut penelitian yang di lakukan oleh Sari dan Fidiana (2017), tax amnesty memiliki pengaruh positif terhadap kepatuhan wajib pajak. Menurut penelitian yang di lakukan Sari dan Fidiana (2017) pengetahuan perpajakan berpengaruh positif terhadap kepatuhan wajib pajak. Menurut Tiraada (2013) kesadaran perpajakan berpengaruh positif terhadap kepatuhan wajib pajak orang pribadi. Hal tersebut menjadi dasar dari penulis untuk melakukan penelitian ini. Penelitian ini merupakan replikasi dari penelitian sebelumnya. Berdasarkan uraian-uraian sebelumnya, maka variabel independen yang di gunakan dalam penelitian ini adalah tax amnesty, pengetahuan perpajakan, kesadaran perpajakan.

Berdasarkan latar belakang di atas dapat di ambil perumusan masalah sebagai berikut: (1) Apakah tax amnesty berpengaruh positif terhadap kepatuhan wajib pajak? (2) Apakah pengetahuan berpengaruh positif terhadap kepatuhan wajib pajak? (3) Apakah kesadaran perpajakan berpengaruh positif terhadap kepatuhan wajib pajak ? 


\section{TINJAUAN PUSTAKA}

\section{Theory Of Planned Behevior (TPB)}

Berdasarkan model TPB, ketentuan perpajakan dapat di patuhi oleh seorang individu apabila di dalam diri sendiri individu tersebut memiliki intention (niat). Menurut Tiraada (2013) munculnya niat untuk berperilaku di tentukan oleh 3 faktor yaitu :

\section{Behavioralbeliefs}

Behavioralbeliefs merupakan keyakinan individu akan hasil dari suatu perilaku dan evaluasi atas hasil tersebut.

2. Normative Beliefs

Normative Beliefs yaitu keyakinan tentang harapan normatif orang lain dan motivasi untuk memenuhi harapan tersebut.

\section{Control Beliefs}

Control Beliefs merupakan keyakinan tentang keberadaan hal-hal yang mendukung atau menghambat perilaku yang akan di tampilkan dan persepsinya tentang seberapa kuat hal-hal yang mendukung dan menghambat perilaku tersebut (perceived power).

\section{Tax amnesty}

Rahayu (2017) Tax Amnesty adalah penghapusan pajak yang seharusnya terutang, tidak di kenai sanksi adminis perpajakan dan sanksi pidana di bidang perpajakan, dengan cara mengungkapkan harta dan membayar utang tebusan sebagaimana di atur dalam Undang-Undang No 11 tahun 2016. Kebijakan pemerintah di bidang perpajakan memberikan pengampuanan pajak yang seharusnya terutang dengan membayar tebusan dengan jumlah tertentu yang bertujuan untuk memberikan kesempatan bagi wajib pajak yang selama ini tidak membayar pajak dengan benar. Menurut Sari dan Fidiana (2017) tax amnesty mempunyai beberapa manfaat. (1) Bagi negara pengampunan pajak dapat meningkatkan tax ratio. (2) bagi wajib pajak yang belum memiliki NPWP pengampunan pajak dapat menghindarkan sanksi pajak. (3) bagi aparat perpajakan pengampunan pajak dapat meningkatkan penerimaan pajak yang lebih optimal.

\section{Pengetahuan perpajakan}


Menurut Sari dan Fidiana (2017) pengetahuan pajak adalah informasi pajak yang dapat digunakan wajib pajak sebagai dasar untuk bertindak, mengambil keputusan, dan untuk menempuh arah atau strategi tertentu sehubungan dengan pelaksanaan hak dan kewajibannya dibidang perpajakan. Terdapat dua fungsi pajak yaitu : (1) Fungsi penerimaan (Budgeter), pajak yang berfungsi sebagai sumber dana yang di peruntukan bagi pembiayaan pengeluaran-pengeluaran pemerintah. Sebagai contoh: di masukanya pajak dalam APBN sebagai penerimaan Negeri. (2) Fungsi mengatur (Reguler), pajak berfungsi sebagai alat untuk mengatur atau melksanakan kebijakan di bidang sosial dan ekonomi. Sebagai contoh: dikenakanya pajak yang lebih tinggi terhadap minuman keras dapat di tekan. Demikian pula terhadap barang mewah yaitu dengan adanya PPnBM (pajak pertambahan barang mewah).

\section{Kesadaran Perpajakan}

Menurut penelitian yang di lakukan oleh Puri (2014) Kesadaran adalah keadaan mengetahui atau mengerti, sedangkan perpajakan adalah perihal pajak. Sehingga kesadaran perpajakan adalah keadaan mengetahui atau mengerti perihal pajak.

\section{Kepatuhan Wajib Pajak}

Menurut penelitian yang di lakukan oleh Puri (2014) Kesadaran adalah keadaan mengetahui atau mengerti, sedangkan perpajakan adalah perihal pajak. Sehingga kesadaran perpajakan adalah keadaan mengetahui atau mengerti perihal pajak. Menurut penelitian yang di lakukan Sari dan Fidiana (2017) ada 2 macam kepatuhan yakni kepatuhan formal dan kepatuhan material. Kepatuhan formal adalah suatu keadaan di mana wajib pajak memenuhi kewajiban secara formal sesuai dengan ketentuan dalam undang-undang perpajakan. Kepatuhan material adalah suatu keadaan di mana wajib pajak secara subtantif atau hakikatnya memenuhi semua ketentuan material perpajakan.

\section{Kerangka pemikiran}

\section{Gambar 1}

\section{Kerangka pemikiran}

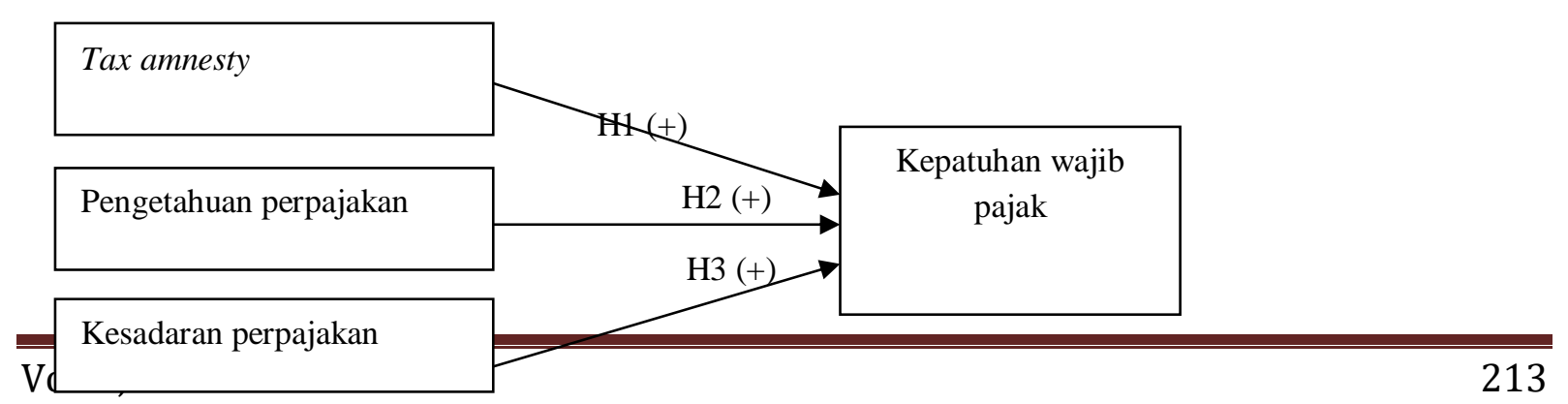




\section{Pengaruh Tax Amnesty terhadap kepatuhan wajib pajak}

Tax amnesty adalah pengahapusan pajak yang seharusnya terutang, tidak di kenai sanksi administrasi perpajakan dan sanksi pidana di bidang perpajakan, dengan cara mengungkap harta dan uang tebusan sebagaimana di atur dalam undang-undang No 11 tahun 2016. Apabila wajib pajak mendapatkan dorongan atau motivasi yang berasal dari luar diri seseorang (orang lain) yang akan mempengarui perilaku wajib pajak tersebut (Normative Beliefs). Maka wajib pajak akan termotivasi dan akan patuh untuk melaporkan penghasilanya dan membayar pajak secara sukarela dan wajib pajak tidak akan menghambat pendapatan asli daerah.

Menurut penelitian yang dilakukan oleh Sari dan Fidiana (2017) tax amnesty berpengaruh positif terhadap kepatuhan wajib pajak. Berdasarkan uraian tersebut dapat di simpulakn sebagai berikut:

H1: Tax amnesty berpengaruh positif terhadap kepatuhan wajib pajak.

\section{Pengaruh pengetahuan perpajakan terhadap kepatuhan wajib pajak}

Pengetahuan perpajakan adalah informasi pajak yang dapat di gunakan wajib pajak sebagai dasar untuk bertindak, mengambil keputusan, dan untuk menempuh arah dan strategi tertentu sehubungan dengan hak dan kewajibanya di bidang perpajakan (Sari dan Fidiana, 2017). Behavioral beliefs adalah keyakinan akan hasil dari suatu perilaku dan evaluasi atas hasil tersebut. Apabila wajib pajak memiliki pengetahuan tentang perpajakan maka wajib pajak akan sadar akan pentingnya membayar pajak.

Menurut penelitian yang dilakukan oleh Sari dan Fidiana (2017) pengetahuan perpajakan berpengaruh positif terhadap kepatuhan wajib pajak. Berdasarkan uraian tersebut dapat di sempulan sebagai berikut :

$\mathrm{H} 2$ : pengetahuan perpajakan berpengaruh positif terhadap kepatuhan wajib pajak.

\section{Pengaruh Kesadaran Perpajakan terhadap kepatuhan wajib pajak}


Kesadaran wajib pajak adalah pemahaman yang mendalam pada seseorang atau badan yang terwujud dalam pemikiran, sikap dan tingkah laku untuk melaksanakan hak dan kewajiban perpajakan sesai dengan ketentuan peraturan perundang-undangan karena memahami pajak sangat penting untuk pembiayaan nasional (Agustiningsih, 2016). Kesadaran perpajakan bisa dikaitkan dengan teori Behavioral Beliefs sebelum wajib pajak melakukan sesuatu wajib pajak tersebut akan memiliki keyakinan mengenai hasil yang akan di peroleh dari perilaku dan evaluasi tersebut. Kemudian wajib pajak akan memtuskan akan melakukannya atau tidak.

Menurut penelitian yang dilakukan oleh Tiraada (2013) Kesadaran perpajakan berpengaruh positif terhadap kepatuhan wajib pajak. Berdasarkan uraian tersebut maka dapat di tulus kesimpulan sebagai berikut :

H4 : Kesadaran perpajakn berpengaruh positif terhadap kepatuhan wajib pajak

\section{METODE PENELITIAN}

\section{Rancangan Penelitian}

Penelitian ini merupakan penelitian dengan cara melakukan penyebaran kuesioner pada objek penelitian di kantor pelayanan pajak KPP Pratama Pati. Penyebaran kuesioner bertujuan untuk memperoleh fakta-fakta dan gejala-gejala pada objek yang bersangkutan.

Objek pada penelitian ini adalah KPP Pratama Pati. Subjek dari penelitian ini adalah Wajib pajak yang terdaftar di KPP Pratama Pati.

\section{Definisi Operasional}

Variabel-variabel dari tax amnesty, pengetahuan perpajakan, kesadaran perpajakan dan kepatuhan wajib pajak dapat di ukur dengan skala likert 5 alternatif jawaban.

Tax amnesty dari penelitian ini di ukur dengan indikator: (1)Wajib pajak mau berpartisipasi dalam program tax amnesty. (2) Tax amnesty bisa meningkatkan kepatuhan wajib pajak. (3) Tax amnesty digunakan untuk melaporkan harta kekayaan wajib pajak. (4)Tax amnesty merupakan alat trasisi menuju sistem perpajakan yang baru. (5)Tax amnesty dapat meningkatkan penerimaan negara. 
Pengetahuan perpajakan dari penelitian ini di ukur dengan indikator: (1) Wajib pajak mengetahui perpajakan yang berlaku. (2) Wajib pajak mengetahui peraturan mengenai batas waktu pelaporan. (3) NPWP sebagai identitas wajib pajak. (4) Pajak merupakan sumber penerimaan negara terbesar. (5) Pajak digunakan untuk pembiayaan oleh pemerintah. (6)Wajib pajak paham dengan sistem perpajakan yang digunakan saat ini.

Kesadaran perpajakan dari penelitian ini di ukur dengan indikator: (1) Kemauan wajib pajak dalam membayar pajak dan melaporkan SPT. (2) Tingkat ketertiban dan kedisiplinan wajib pajak dalam membayar pajak.

Kepatuhan wajib pajak dari penelitian ini di ukur dengan indikator: Wajib pajak paham dan berusaha memahami UU perpajakan. (2) Wajib pajak mengisi formulir pajak dengan benar. (3) Wajib pajak selalu patuh membayar pajak sesuai dengan nominal yang sebenarnya. (4) Wajib pajak selalu membayar pajak tepat waktu. (5) Wajib pajak selalu melaporkan pajak tepat waktu.

\section{Populasi}

Populasi dalam penelitian ini adalah wajib pajak, baik wajib pajak orang pribadi maupun wajib pajak badan yang terdaftar di KPP Pratama Pati.

\section{Sampel}

Dalam penelitian ini menggunakan accidental sampling adalah teknik penentuan sampel berdasarkan kebetulan saja, anggota populasi yang di temui penelitin dan bersedia menjadi responden di jadikan sampel. Sampel yang di ambil adalah 100 wajib pajak yang ada di Kpp pratama Pati.

\section{Teknis Analisis Data}

Penelitian ini menggunakan metode kuantitatif. Metode analisis yang di gunakan yaitu analisis statistik yang di perhitungkan dengan menggunakan SPSS 23. Alat analisis yang digunakan dalam penelitian yaitu analisis regresi linier berganda karena variabel independen penelitian ini lebih dari satu variabel.

\section{Uji Validitas dan Reliabilitas}


Berdasarkan nilai person corelation di peroleh hasil bahwa item-item peryataan pada penelitian yang dilakukan adalah valid, hal ini dapat dilihat dari nilai person corelation lebih besar dari nilai $r_{\text {tabel. }}$ Sedangkan pada uji reliabilitas nilai cronbach alpha lebih besar dari 0,60, dengan demikian dapat disimpulkan bahwa pada item-item penelitian ini dinyatakan reliabel.

\section{Uji asumsi klasik}

\section{Uji multikolonieritas}

Tabel 1

Uji multikolonieritas

\begin{tabular}{|l|l|l|}
\hline \multicolumn{1}{|c|}{ Variabel } & \multicolumn{1}{|c|}{ Tolerance } & VIF \\
\hline Tax amnesty & 0,698 & 1,432 \\
Pengetahuan perpajakan & 0,891 & 1,122 \\
Kesadaran perpajakan & 0,746 & 1,340 \\
\hline
\end{tabular}

Dari tabel di atas dapat dilihat bahwa nilai VIF pada ketiga variabel bebas kurang dari 10, dan nilai tolerance $>0,10$. Jadi dapat disimpulkan bahwa tidak terjadi multikolonieritas. Sehingga model regresi di katakan baik.

\section{Uji Heteroskedastisitas}

Tabel 2

Uji Heteroskedastisitas

\begin{tabular}{|c|c|c|c|c|c|c|c|c|}
\hline & & \multicolumn{3}{|c|}{ Coefficients $^{a}$} & \multirow[b]{3}{*}{$\mathrm{t}$} & \multirow[b]{3}{*}{ Sig. } & & \\
\hline \multirow[b]{2}{*}{ Model } & & \multicolumn{2}{|c|}{$\begin{array}{c}\text { Unstandardized } \\
\text { Coefficients }\end{array}$} & $\begin{array}{l}\text { Standardized } \\
\text { Coefficients }\end{array}$ & & & \multicolumn{2}{|c|}{ Collinearity Statistics } \\
\hline & & B & Std. Error & Beta & & & $\begin{array}{c}\text { Toleranc } \\
\mathrm{e}\end{array}$ & VIF \\
\hline 1 & (Constant) & 021 & 1,721 & &, 012 & ,990 & & \\
\hline & TAX AMNESTY & ,063 & 054 &, 140 & 1,169 & 245 & 698 & 1,432 \\
\hline & $\begin{array}{l}\text { PENGETAHUAN } \\
\text { PERPAJAKAN }\end{array}$ & ,083 & ,073 &, 120 & 1,137 & ,258 & ,891 & 1,122 \\
\hline & $\begin{array}{l}\text { KESADARAN } \\
\text { PERPAJAKAN }\end{array}$ &,- 114 & 077 &,- 171 & $-1,478$ & ,143 & ,746 & 1,340 \\
\hline
\end{tabular}


Dari tabel di atas dapat disimpulkan bahwa pada uji heteroskedastisitas nilai signifikasi lebih dari 0,05 , itu menunjukan bahwa item-item penelitian tidak terjadi heteroskedastisitas.

\section{Uji Normalitas}

Tabel 3

Uji kolmogorof-smirnov

One-Sample Kolmogorov-Smirnov Test

\begin{tabular}{|ll|r|}
\hline & & $\begin{array}{c}\text { Unstandardized } \\
\text { Residual }\end{array}$ \\
\hline $\mathrm{N}$ & Mean & 100 \\
Normal Parameters & a,b &, 0000000 \\
Most Extreme Differences & Std. Deviation & 1,43599611 \\
& Positive &, 085 \\
& Negative &, 053 \\
Test Statistic & &,- 085 \\
Asymp. Sig. (2-tailed) & &, 085 \\
\end{tabular}

Dari tabel di atas dapat disimpulkan bahwa nilai kolmogorof-smirnov memiliki nilai 0,074 yang lebih besar dari 0,05, maka dapat disimpulkan bahwa uji kolmogorof-smirnov baik atau normal.

\section{Analisis Regresi Linier Berganda}

Tabel 4

Analisis regresi

\begin{tabular}{|c|c|c|c|c|c|c|}
\hline \multicolumn{7}{|c|}{ Coefficients $^{\mathrm{a}}$} \\
\hline \multirow{2}{*}{\multicolumn{2}{|c|}{ Model }} & \multicolumn{2}{|c|}{ Unstandardized Coefficients } & \multirow{2}{*}{$\begin{array}{c}\text { Standardized } \\
\text { Coefficients } \\
\text { Beta } \\
\end{array}$} & \multirow[b]{2}{*}{$\mathrm{T}$} & \multirow[b]{2}{*}{ Sig. } \\
\hline & & $\mathrm{B}$ & Std. Error & & & \\
\hline & (Constant) & 10,717 & 3,078 & & 3,482 & 001 \\
\hline & TAX AMNESTY &,- 006 & 097 &,- 007 &,- 065 & ,948 \\
\hline
\end{tabular}




\begin{tabular}{|l|r|r|r|r|r|}
\hline PENGETAHUAN &, 248 &, 131 &, 191 & 1,887 &, 062 \\
PERPAJAKAN &, 327 &, 138 &, 262 & 2,366 &, 020 \\
KESADARAN & & & & \\
PERPAJAKAN &, 327 &
\end{tabular}

a. Dependent Variable: KEPATUHAN WAJIB PAJAK

Berdasarkan tabel di atas dapat di bentuk persamaan regresi sebagai berikut:

$\mathrm{KWP}=10,717-0,006 \mathrm{TA}+0,248 \mathrm{PP}+327 \mathrm{KP}+\mathrm{e}$

Keterangan:

KWP : Kepatuhan wajib pajak

TA : tax amnesty

PP : Pengetahuan perpajakan

KP : Kesadaran Perpajakan

\section{Uji Hipotesis}

\section{Koefisien Determinasi $\left(\mathbf{R}^{2}\right)$}

Tabel 5

Koefisien Determinasi $\left(\mathrm{R}^{2}\right)$

\begin{tabular}{|l|r|r|r|r|}
\hline Model & \multicolumn{1}{|c|}{$\mathrm{R}$} & R Square & \multicolumn{1}{c|}{$\begin{array}{c}\text { Adjusted R } \\
\text { Square }\end{array}$} & $\begin{array}{l}\text { Std. Error of the } \\
\text { Estimate }\end{array}$ \\
\hline 1 &, $351^{\mathrm{a}}$ &, 123 &, 096 & 1,458 \\
\hline
\end{tabular}

a. Predictors: (Constant), KESADARAN PERPAJAKAN,

PENGETAHUAN PERPAJAKAN, TAX AMNESTY

Dari tabel di atas di peroleh angka $\mathrm{R}^{2}$ sebesar 0,096 atau $(9,6 \%)$ hal ini menunjukan bahwa variabel independen yaitu tax amnesty, pengetahuan perpajakan, kesadaran perpajakan, memiliki nilai sebesar 9,6\% sedangkan sisanya 90,4\% di pengarui oleh variabel lain yang tidak dijelaaskan dalam penelitian.

\section{Uji F}


Tabel 6

Uji F

ANOVA $^{\mathrm{a}}$

\begin{tabular}{|ll|r|r|r|r|r|}
\hline Model & & Sum of Squares & Df & Mean Square & F & Sig. \\
\hline 1 & Regression & 28,694 & 3 & 9,565 & 4,498 &, $005^{\mathrm{b}}$ \\
& Residual & 204,146 & 96 & 2,127 & & \\
& Total & 232,840 & 99 & & & \\
\hline
\end{tabular}

Hasil uji koefisien regresi (uji F) secara bersama-sama di peroleh F hitung sebesar 4,498 df1 sebesar 5 dan df2 sebesar 94 sedangkan $\mathrm{F}$ tabel sebesar 2,31 dan signifikasi sebesar 0,002. Berdasarkan data tersebbut $\mathrm{F}$ hitung $>\mathrm{F}$ tabel yaitu 4,498 $>$ 2,31 dan nilai signifikasi $0,002<$ nilai alpha 0,005. Maka dapat disimpulkan bahwa seluruh variabel independen secara simultan (bersama-sama) berpengaruh terhadap variabel dependen.

\section{Uji t}

Tabel 7

Uji t

\begin{tabular}{|c|c|c|c|c|c|c|}
\hline \multicolumn{7}{|c|}{ Coefficients $^{\mathrm{a}}$} \\
\hline \multirow{2}{*}{\multicolumn{2}{|c|}{ Model }} & \multicolumn{2}{|c|}{ Unstandardized Coefficients } & \multirow{2}{*}{$\begin{array}{c}\text { Standardized } \\
\text { Coefficients } \\
\text { Beta }\end{array}$} & \multirow[b]{2}{*}{$\mathrm{T}$} & \multirow[b]{2}{*}{ Sig. } \\
\hline & & $\mathrm{B}$ & Std. Error & & & \\
\hline \multirow[t]{6}{*}{1} & (Constant) & 10,717 & 3,078 & & 3,482 &, 001 \\
\hline & TAX AMNESTY &,- 006 & ,097 &,- 007 &,- 065 & ,948 \\
\hline & PENGETAHUAN & & 121 & & 1007 & 067 \\
\hline & PERPAJAKAN &, 248 &, 131 &, 191 & 1,881 &, 002 \\
\hline & KESADARAN & 227 & 120 & & 266 & תרת \\
\hline & PERPAJAKAN & 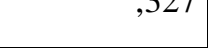 &, 150 &, 202 & 2,500 &, $0<0$ \\
\hline
\end{tabular}

a. Dependent Variable: KEPATUHAN WAJIB PAJAK

Berdasarkan tabel 8 dapat disimpulkan bahwa:

Pertama: Berdasarkan dari hasil analisis regresi yang dilakukan dengan melihat dari tabel

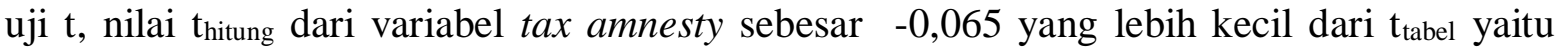
$1,984(-0,065<1984)$ dengan nilai signifikansi sebesar 0,948 yang lebih besar dari taraf signifikan yaitu $0,05(0,948>0,05)$. Maka $\mathrm{H}_{1}$ artinya variabel tax amnesty tidak berpengaruh 
dan tidak signifikan terhadap kepatuhan wajib pajak. Apabila wajib pajak memiliki dorongan atau motivasi dari luar diri seseorang yang akan mempengarui perilaku wajib pajak tersebut. Bagi sebagian masarakat miskin dengan adanya tax amnesty malah di anggap tidak adil dam justru malah memberikan keuntungan bagi kalangan atas, karena tax amnesty di ber lakukan secara seimbang bagi kalangan atas maupun kalangan miskin.

Kedua : Berdasarkan dari hasil analisis regresi yang dilakukan dengan melihat dari tabel uji $\mathrm{t}$, nilai $t_{\text {hitung }}$ dari variabel pengetahuan perpajakan sebesar 1,887 yang lebih kecil dari $t_{\text {tabel }}$ yaitu $1,984(1,887<1,984)$ dengan nilai signifikasi sebesar 0,062 yang lebih besar dari taraf signifikan yaitu $0,05(0,062>0,05)$. Maka $\mathrm{H}_{2}$ berarti pengetahuan perpajakan tidak berpengaruh dan tidak signifikan terhadap kepatuhan wajib pajak. Apabila wajib pajak memiliki pengetahuan yang cukup luas tentang pentingnya membayar pajak tetapi wajib pajak tetap tidak memiliki keinginan untuk membayar pajak maka wajib pajak tidak akan patuh terhadap kewajiban perpajakannya.

Ketiga: Berdasarkan dari hasil analisis regresi yang dilakukan yang dilihat dari uji t, nilai $\mathrm{t}_{\text {hitung }}$ dari variabel kesadaran perpajakan sebesar 2,366 yang lebih besar dari $t_{\text {tabel }}$ yaitu 1,984 (2,366>1,984) dengan nilai signifikan sebesar 0,020 yang lebih kecil dari taraf 0,05 $(0,020<0,05)$. Maka $\mathrm{H}_{1}$ artinya variabel kesadaran perpajakan berpengaruh positif dan signifikan terhadap kepatuhan wajib. Apabila wajib pajak sadar akan pentingnya membayar pajak sebagai pendapatan negara, maka kepatuahn wajib pajak akan meningkat.

\section{KESIMPULAN}

Berdasarkan dari hasil analisis regresi yang dilakukan dengan melihat dari tabel uji t, nilai $t_{\text {hitung }}$ dari variabel tax amnesty sebesar -0,065 yang lebih kecil dari $t_{\text {tabel }}$ yaitu 1,984 (0, 065 <1984) dengan nilai signifikansi sebesar 0,948 yang lebih besar dari taraf signifikan yaitu $0,05(0,948>0,05)$. Maka $\mathrm{H}_{1}$ artinya variabel tax amnesty tidak berpengaruh dan tidak signifikan terhadap kepatuhan wajib pajak. itu berarti $\mathrm{H}_{0}$ ditolak. Berdasarkan dari hasil analisis regresi yang dilakukan dengan melihat dari tabel uji $t$, nilai $t_{\text {hitung dari variabel }}$ pengetahuan perpajakan sebesar 1,887 yang lebih kecil dari tabel yaitu 1,984 (1, $887<1,984)$ dengan nilai signifikasi sebesar 0,062 yang lebih besar dari taraf signifikan yaitu $0,05(0$, 062>0,05). Maka $\mathrm{H}_{2}$ berarti pengetahuan perpajakan tidak berpengaruh dan tidak signifikan terhadap kepatuhan wajib pajak. itu berarti $\mathrm{H}_{0}$ ditolak. Berdasarkan dari hasil analisis regresi yang dilakukan yang dilihat dari uji $\mathrm{t}$, nilai $\mathrm{t}_{\text {hitung }}$ dari variabel kesadaran perpajakan sebesar 2,366 yang lebih besar dari tabel yaitu 1,984 $(2,366>1,984)$ dengan nilai signifikan sebesar 
0,020 yang lebih kecil dari taraf $0,05(0,020<0,05)$. Maka $\mathrm{H}_{1}$ artinya variabel kesadaran perpajakan berpengaruh positif dan signifikan terhadap kepatuhan wajib. itu berarti $\mathrm{H}_{0}$ diterima

\section{Saran}

Pertama : Rendahnya nilai Adjusted $R$ Square berarti kepatuhan wajib pajak tidak dapat di jelaskan seluruhnya oleh variabel tax amnesty, pengetahuan perpajakan, pelayanan fiskus, kesadaran perpajakan, sanksi perpajakan sehingga Peneliti selanjutnya bisa menambahkan variabel independen lain seperti sosialisasi perpajakan dan penerapan E-filing. Sosialisasi perpajakan bisa digunakan agar wajib pajak lebih paham tentang pentingnya membayar pajak. Penerapan E-filing agar lebih memudahkan wajib pajak dalam membayar pajak, selain itu juga lebih menyingkatkan waktu bagi wajib pajak. Kedua : Untuk peneliti selanjutnya dapat di tujukan kepada wajib pajak yang memiliki UMKM atau terjun ke lapangan secara langsung, selain itu juga dapat tunjukan kepada pelayan fiskus.

\section{DAFTAR PUSTAKA}

Abdillah, Willy dan Jogiyanto. 2011. Sistem Tatakelola Teknologi Informasi. ANDI. Yogyakarta

Agoes, Sukrisno dan Estralita Trisnawati. 2012. Akuntansi Perpajakan edisi 2 Revisi. Salemba Empat

Arum, Harjanti Puspa. 2012. Pengaruh Kesadaran Wajib Pajak, Pelayanan Fiskus, dan Sanksi Pajak terhadap Kepatuhan Wajib Pajak Orang Pribadi yang Melakukan Kegiatan Usaha dan Pekerjaan Bebas (Studi di Wilayah KPP Pratama Cilacap). Skripsi Universitas Diponegoro

Bungin, Burhan. 2005. Metodelogi Penelitian Kuantitatif. Kencana.

Dermawan, Deni. 2013. Metode Penelitian Kuantitatif. PT Remaja Rosdakarya

Forum pajak. 2016. Fasilitas pengampunan pajak. http:forumpajak.org/fasilitaspengampunan-pajak-tax-amnesty/.

Ghozali, Imam. 2016. Aplilasi Analisis Multivariete dengan Program IBM SPSS 23. Badan Penerbit Universitas Diponegoro.

Ilyas, Wirawan B dan Richard burton. 2013. Hukum Pajak. Salemba Empat

Kementrian Keuangan Republik Indonesia. 2016.Nota Keuangan dan Rancangan Anggaran Pendapatan dan Belanja Tahun Anggaran 2016. https://www.kemenkeu.go.id/sites/default/files/bibfinal.pdf. 4desember2017(10:07) 
Khasanah, Septiyani Nur. 2014. Pengaruh Pengetahuan Perpajakan, Modernisasi Sistem Administrasi Perpajakan, dan Kesadaran Wajib Pajak terhadap Kepatuahan Wajib pajak pada Kantor Wilayah Direktorat Jendral Pajak Daerah Istimewa Yogyakarta tahun 2013. Sekripsi Universitas Negeri Yogyakarta.

Kuncoro, Mudrajad. 2003. Metode Riset untuk Bisnis dan Ekonomi. Erlanga

Kundalini, Pertiwi. 2016. Pengaruh Kesadaran Wajib Pajak dan Pelayanan Pegawai Pajak terhadap Kepatuhan Wajib Pajak pada Kantor Pelayanan Pajak Pratama Kabupaten Temanggung Tahun 2015. Sekripsi Universitas Negeri Yogyakarta.

Madiasmo. 2005. Perpajakan Edisi Revisi. ANDI. Yogyakarta.

Muljono, Djoko. 2008. Ketentuan Umum Perpajakan. ANDI Yogyakarta.

Ngadiman, dan Daniel Huslin. 2015. Pengaruh Sunset Policy, Tax Amnesty, dan Sanksi Pajak terhadap Kepatuhan Wajib Pajak (Studi Empiris di Kantor Pelayanan Pajak Pratama Jakarta Kembangan). Jurnal Akuntansi, vol 12: 225-241

Paramartha, I Putu Indra Pradnya dan Rasmini Ni Ketut Rasmini. 2016. Pengaruh Kualitas Pelayanan, Pengetahuan dan Sanksi Perpajakan pada Kepatuhan Wajib Pajak Badan. E-Jurnal Akuntansi Universitas Udayana Vol.15:641-666

Pratami, Nanda Aricha, Sri Hatono, Eny Kustiyah. 2017. Pengaruh kebijakan, kesadaran, pelayanan, dan informasi tax amnesty terhadap kepatuhan wajib pajak pada KPP Pratama Surakarta. Vol 17 No. 2 (300-307)

Puri, Kurnia Asrining. 2014. Pengaruh Kesadaran Wajib Pajak, Pelayanan Fiskus, dan Sanksi Pajak terhadap Kepatuhan Wajib Pajak Orang Pribadi yang Melakukan Kegiatan Usaha dan Pekerjaan Bebas. Sekripsi Universitas Muhammadiyah Surakarta.

Rahayu, Nurulita. 2017. Pengaruh Pengetahuan Perpajakan, Ketegasan Sanksi Pajak, dan Tax Amnesty terhadap Kepatuhan Wajib Pajak. Akuntansi Dewantara Vol. 1 No. 1

Resmi, Siti. 2014. Perpajakan. Salemba Empat, Jakarta Selatan

Sari, Viega Ayu Permata, dan Fidiana. 2017. Pengaruh Tax Amnesty, Pengetahuan Perpajakan, dan Pelayanan Fiskus terhadap Kepatuhan Wajib Pajak. Jurnal ilmu dan riset akuntansi Volume 6, Nomer 2, Februari 2017.

Suandy, Erly. 2014. Hukum Pajak. Salemba Empat

Supramono, dan Theresia Woro Damayanti. 2005. Perpajakan Indonesia. ANDI Yogyakarta.

Tiraada, Tryana A.M. 2013. Kesadaran Perpajakan, Sanksi pajak, Sikap Fiskus terhadap Kepatuhan WPOP di Kabupaten Minahasa Selatan. Jurnal EMBA, Vol 1 No. 3: 9991008 
